\title{
Uji Model Keberhasilan Sistem Informasi: Media Penyimpanan Google Drive
}

\author{
Agustinus Rio Trilaksono $^{1}$, T. Husain ${ }^{2}$, Rouly Doharma ${ }^{3}$ \\ ${ }^{1}$ Sistem Informasi, STMIK Swadharma, Jalan Malaka No. 3 (Kota Tua), Jakarta Barat - 11230 \\ ${ }^{2,3}$ Sistem Informasi, STMIK Widuri, Jalan Palmerah Barat No. 353, Jakarta Selatan - 12210 \\ e-mail: ${ }^{1}$ agustinusrio@yahoo.com, ${ }^{2}$ thusain050686@gmail.com, ${ }^{3}$ rouly.doharma@gmail.com
}

Submitted Date: February $09^{\text {th }}, 2020$

Revised Date: April 15 ${ }^{\text {th }}, 2020$
Reviewed Date: February $19^{\text {th }}, 2020$

Accepted Date: April 29 $9^{\text {th }}, 2020$

\begin{abstract}
The era of ICT-based information (information and communication technology), information becomes an absolute primary means for users decent individuals and organizations as a medium of exchange and interaction. Google Drive is one of the internet-based services application that allows users to make storage media as a resources. The destination of this research to calibration the IS Success Model of Google Drive as a storage medium among college students with the elements i.e. Information Quality, System Quality and Service Quality. The research method used a quantitative approach with questionnaires as a means of data collection. The number of samples counted by 77 respondents. The data analysis methods using structural equation modeling by Lisrel Version 8.72 through descriptive statistic analysis, test of quality instrument, goodness-of fit model, and hypotesis test. The findings represent that the IS Success Model prove significant influence on Satisfaction of college student through Information Quality and System Quality while Quality Service is not significant influence. Service Quality and System Quality are the most effective variables affecting Satisfaction of college student with correlation coefficient in the amount of 67,8 percent and 66,5 percent.
\end{abstract}

Keywords: Google Drive, IS Success Model, Satisfaction

\section{Abstrak}

Era informasi berbasis ICT (information and communication technology), informasi menjadi sarana utama yang mutlak bagi pengguna baik individu maupun organisasi sebagai media pertukaran dan berinteraksi. Google Drive merupakan salah satu aplikasi layanan berbasis internet yang memungkinkan pengguna (user) dapat menjadikan media penyimpanan (storage) sebagai sumberdaya. Tujuan penelitian ini untuk menguji model keberhasilan sistem informasi Google Drive sebagai media penyimpanan di kalangan mahasiswa dengan faktor yang terdiri dari Kualitas Informasi, Kualitas Sistem dan Kualitas Layanan. Metode penelitian menggunakan pendekatan kuantitatif dengan kuesioner sebagai alat pengumpulan data. Jumlah sampel yang digunakan adalah 77 responden. Metode analisis data menggunakan model persamaan struktural dengan Lisrel Version 8.72 melalui analisis statistif deskriptif, uji kualitas instrumen penelitian, uji kesesuaian model, dan uji hipotesis. Temuan penelitian menunjukkan bahwa model keberhasilan sistem informasi membuktikan pengaruh signifikan terhadap Kepuasan Mahasiswa melalui faktor Kualitas Informasi dan Kualitas Sistem sementara Kualitas Layanan tidak. Kualitas Layanan dan Kualitas Sistem adalah variabel yang paling efektif berpengaruh terhadap Kepuasan Mahasiswa dengan nilai koefisien korelasi masing-masing 67,8 persen dan 66,5 persen.

Kata Kunci: Google Drive, Model Keberhasilan Sistem Informasi, Kepuasan

\section{Pendahuluan}

Era informasi berbasis ICT (information

and communication technology), informasi menjadi sarana utama yang mutlak bagi pengguna baik individu maupun organisasi sebagai media pertukaran dan berinteraksi. Di samping itu, teknologi informasi memiliki fungsi penyedia dan pengolahan informasi dalam berbagai aktivitas atau penugasan (Hanum \& Saifudin, 2019). Pertukaran dan pengolahan informasi melibatkan 
platform internet dan perangkat lainnya bagi masyarakat informasi khususnya para akademisi untuk mencari berbagai kebutuhan yang melibatkan adanya eksistensi mesin pencari. Sebagai contoh, produk layanan Google adalah salah satu mesin penjelajah (search engine) yang sangat terkenal, platform ini sangat mudah digunakan khususnya para akademisi untuk mencari referensi sumber pustaka seperti bahan makalah, paper, buku hingga artikel jurnal yang dipublikasi di seluruh belahan dunia (Husain T., 2019) dan media penyimpanannya menggunakan fitur Google Drive. Alternatif penyimpanan dokumen berbasis digital ini memiliki manfaat yang dianggap abadi, tidak hilang dan dapat diakses kapan saja, layanan ini banyak dimanfaatkan oleh kalangan akademisi yang dirilis oleh perusahaan Google, Inc pada bulan April 2012.

Aplikasi ini terintegrasi dengan fitur Google lainnya seperti akun Google Plus, akun Gmail, Google Search yang bersumber dari Google Docs versi gratis dengan kapasitas penyimpanan hingga 15 gigabyte (GB). Keunggulan Google Drive yaitu berbasis OCR (optical character recognition) untuk mendeteksi file berformat .pdf dan teks berbentuk gambar (Google Developer, 2018), Google Drive juga dapat melakukan indeksisasi secara otomatif terhadap objek (orang maupun konten-konten file seperti .html, xml, .txt dan jenis lainnya. Fitur App. pada Google Drive memungkinkan diakses via internet dan terpasang di akun Gmail pengguna selain sebagai media pembuatan dan penyimpanan dokumen juga memiliki versi mobile dengan pilihan fitur tambahan yaitu Google spreadsheet, Google docs, Google slide serta Google Forms (Hamdani \& Kaburuan, 2017).

Penelitian ini dimotivasi beberapa peneliti terdahulu yaitu dengan tujuan pemanfaatan groupware pada Google Drive untuk menyelesaikan Tugas Kelompok Siswa. Metode pengumpulan data melalui observasi langsung pada produk berdasarkan instrumen $3 \mathrm{C}$ Triangle (communicatioan, coordination, dan collaboration) dengan temuan penelitian Google Drive merupakan groupware yang memenuhi syarat serta dapat dimanfaatkan siswa sebagai media penyelesaian tugas kelompok siswa dengan kemudahan antarmuka dan sistem kerja yang disediakan oleh layanan (Primawati, 2015).

Kualitas sistem informasi yang diterapkan pada cyber campus (SISCYA) dengan memodifikasi konstruk Webqual 4.0 yaitu pada dimensi kualitas antarmuka pengguna yang menghasilkan temuan penelitian bahwa kualitas yang dipersepsikan dan kualitas layanan pengguna berpengaruh terhadap kepuasan mahasiswa yang berimplikasi pada loyalitas pengguna (Kartikasari, 2017). Layanan Google Scholar sebagai bahan referensi dengan konstruk masing-masing kualitas informasi, sistem dan layanan yang juga temuan penelitian ini tidak mengevaluasi atas model keberhasilan sistem informasi DeLone dan McLean secara menyeluruh, hanya faktor kualitas sistem yang mampu memediasi pengaruh eksternalitas jaringan terhadap kepuasan mahasiswa sementara faktor kualitas informasi dan kualitas layanan tidak membuktikan pengaruh langsung dan tidak langsung (Husain T. , 2019). Persamaan penelitian ini dengan peneliti terdahulu yaitu tetap menggunakan subjek penelitian yaitu mahasiswa. Beragamnya hasil penelitian terdahulu menjadi penting untuk dikaji lebih lanjut agar dapat memperkaya applied theory khususnya mengenai model keberhasilan sistem informasi pengguna layanan di Indonesia.

Penelitian ini mengkaji kembali model keberhasilan sistem informasi dengan tetap mempertahankan konstruk utama model keberhasilan sistem informasi yaitu kualitas informasi, kualitas sistem dan kualitas layanan untuk menguji efektivitas penggunaan layanan Google Drive sebagai media penyimpanan terhadap kepuasan mahasiswa. Software Lisrel Versi 8.72 yang digunakan untuk mengevaluasi konstruk dan pembuktian hipotesis pada penelitian ini.

\section{Kajian Teori}

Google Drive adalah salah satu fasilitas layanan media penyimpanan berbasis web yang dapat diakses secara bebas menggunakan browser Chrome terbaru dan Email. Manfaat penggunaan Google Drive antara lain (1) pengiriman jenis file; (2) sinkronisasi folder; (3) perubahan menggunakan Google aplikasi seperti form, pengolahan kata dan penyajian persentasi; (4) pemberian hak akses; dan (5) penyediaan media penyimpanan yang besar (Prihandi, 2017). Google Drive diwajibkan untuk membuat akun email terlebih dahulu yang selanjutnya dapat dipindahkan ke tab baru pada halaman Google Drive. 


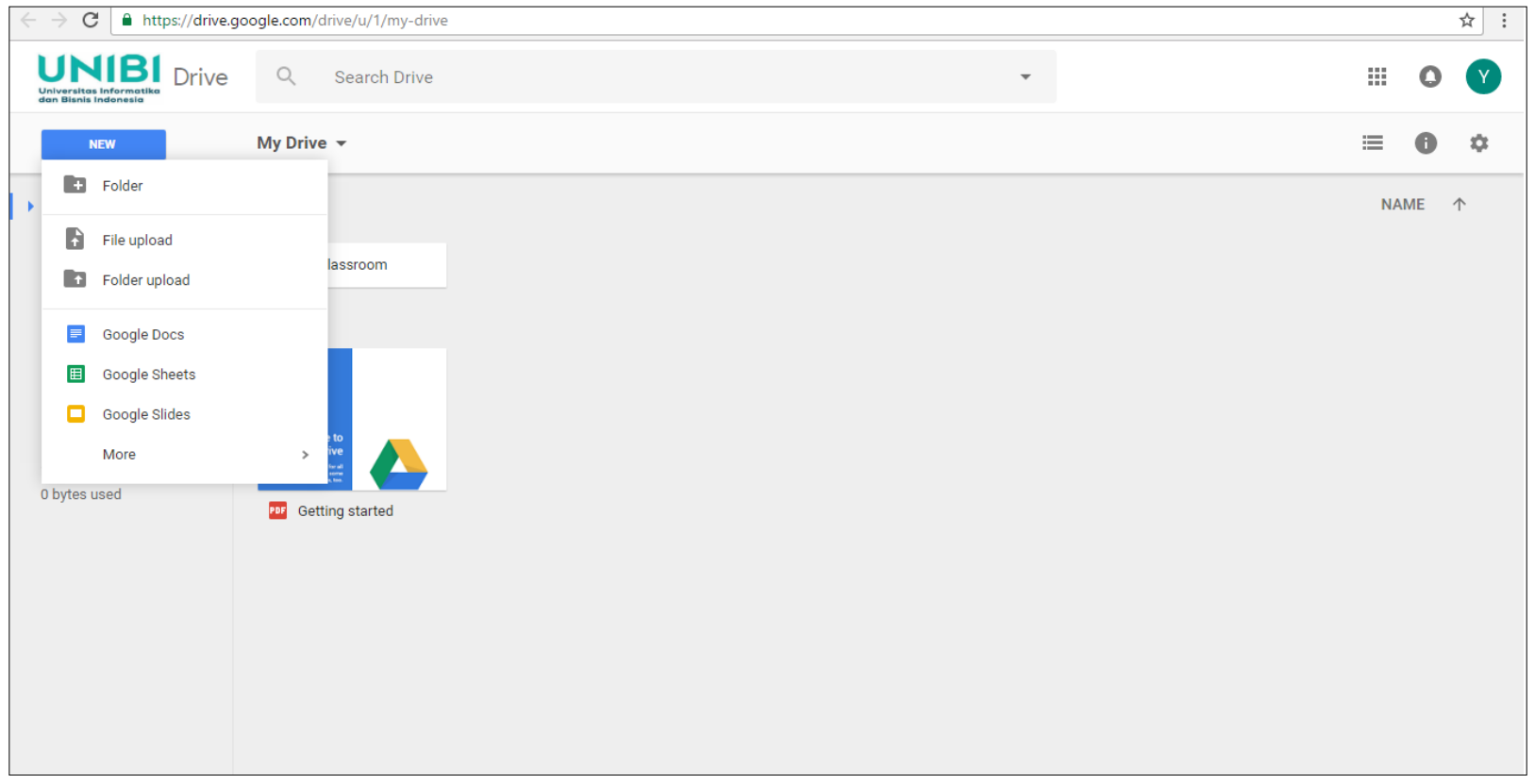

Gambar 1. Ilustrasi tampilan halaman Google Drive (Hamdani \& Kaburuan, 2017)

Fasilitas layanan Google Drive antara lain ikon grid yang ditampilkan berupa file atau berkas yang berukuran besar atau sebagai list gambar (bentuk gambar). Fitur list ini akan memperlihatkan siapa pemilik berkas perubahan terakhir file atau berkas tersebut. Fitur selanjutnya menampilkan pratinjau laman pertama berkas melalui ikon grid. Tombol share dengan hak akses pengaturan dan penyuntingan dokumen dapat dipilih untuk sharing-file serta URL dalam bentuk format .docx spreadsheet atau presentasi dapat dilakukan dengan cara can edit (siapapun yang memiliki tautan dapat menyunting file), can comment (siapapun yang memiliki tautan dapat memberikan komentar); dan can view (siapapun yang memiliki tautan dapat melihat) (Hamdani \& Kaburuan, 2017).

Model Keberhasilan Sistem Informasi (atau IS Success Model diinisiasi oleh William H. Delone dan Ephraim R. McLean pada tahun 1992, kemudian pada tahun 2003 dengan istilah "D\&M IS Success Model". Model penelitian ini dirumuskan dengan konstruk:

1. Kualitas Informasi berfungsi untuk mengukur output dengan pengukuran kesempurnaan, kemudahan pemahaman, personalisasi, relevansi, dan keamanan.

2. Kualitas Sistem berfungsi untuk mengukur penggunaan sistem dengan pengukuran kemampuan adaptasi, ketersediaan, kehandalan, respon waktu, dan kegunaannya.
3. Kualitas Layanan berfungsi untuk mengukur layanan dengan pengukuran penilaian, empati, dan responsif.

4. Kepuasan mahasiswa berfungsi untuk mengetahui respon pengguna terhadap output model keberhasilan sistem informasi secara keseluruhan. Proksi yang digunakan meliputi pembelian kembali, kunjungan kembali, dan survei pengguna (Delone \& McLean, 2003).

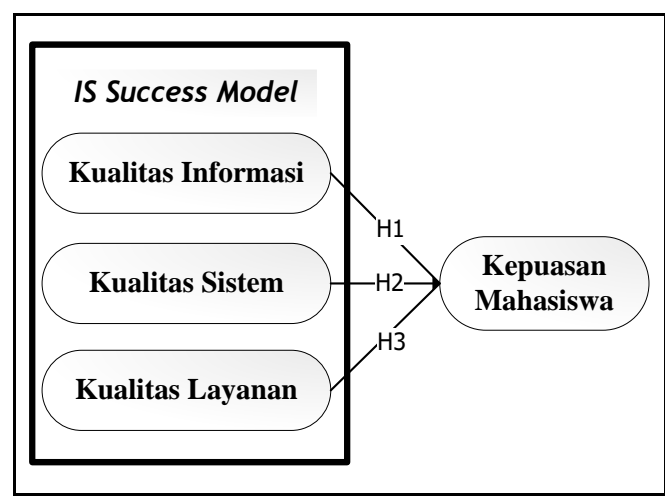

Gambar 2. Adopted by (Delone \& McLean, 2003; Kartikasari, 2017)

Model penelitian di atas diturunkan ke dalam hipotesis alternatif berikut ini:

$\mathrm{H}_{1}$ diduga adanya pengaruh kualitas informasi pada kepuasan mahasiswa

$\mathrm{H}_{2}$ diduga adanya pengaruh kualitas sistem pada kepuasan mahasiswa 
$\mathrm{H}_{3}$ diduga adanya pengaruh kualitas layanan pada kepuasan mahasiswa

\section{Metode Penelitian}

Penelitian ini adalah riset kausalitas (causal effect) yang bertujuan menduga penyajian hipotesis berdasarkan analisis hubungan sebab akibat antar beberapa variabel bebas dengan satu variabel terikat yang berfungsi mempengaruhi dan yang dipengaruhi. Metode menggunakan pendekatan penelitian kuantitatif karena mencakup pengumpulan dan analisis data dengan pengujian statistik (Ali \& Limakrisna, 2013). Data primer menggunakan kuesioner versi online dengan URL http://bit.ly/2tHqgqU yang didistribusikan kepada mahasiswa secara acak. Variabel penelitian dibangun melalui beberapa variabel manifes (indikator) berikut ini:

1. Kualitas Informasi (INQUA) dikonstruk dengan 5 (lima) variabel manifes (X1-X5)

2. Kualitas Sistem (SYSQUA) dikonstruk 5 (lima) variabel manifes yaitu X6-X10

3. Kualitas Layanan (SERQUA) dikonstruk melalui 3 (tiga) variabel manifes yaitu X11X13

4. Kepuasan Mahasiswa (SAT) dikonstruk melalui 3 (tita) variabel manifes yaitu Y1-Y3

Penggunaan skala Ordinal - Likert "skor 14" dengan kategori jawaban Sangat Tidak Setuju, Tidak Setuju, Setuju dan Sangat Setuju dipertimbangkan untuk mengurangi adanya responden yang memilih kategori jawaban "RaguRagu / Netral". Penetapan sampel menggunakan metode purposive sampling dengan persyaratan: (1) mahasiswa tingkat D3, S1 dan S2 yang menggunakan layanan Google Drive lebih dari 1 (satu) bulan; (2) mahasiswa STMIK jurusan sistem informasi dan teknik informatika; dan (3) mahasiswa tersebut berdomisili tinggal di Jakarta Barat.

Metode analisis data menggunakan model persamaan struktural (structural equation modeling) untuk mengevaluasi konstruk yang dirumuskan pada penelitian ini. Pengujian diawali dengan validitas dan reliabilitas instrumen dengan teknik analisis faktor konfirmatori yang mensyaratkan nilai harus lebih besar dari 0,3 dan idealnya lebih besar dari 0,5 dan ukuran reliabilitas komposit / konstruk) atau composite / construct realibility (CR) dengan ketentuan uji harus lebih besar dari sama dengan $(\geq)$ 0,7 (Hair, Black, Babin, \& Anderson, 2010), tetapi nilai reliabilitas dapat diinterpretasikan dan dikatakan baik, jika nilainya lebih besar (>) 0,40 (Tentama \& Subardjo, 2018). Selanjutnya, estimasi model mensyaratkan nilai residual yang kecil atau mendekati nilai 0 (nol) dan dapat mempertimbangkan perlu atau tidaknya adanya modifikasi pada sebuah model dengan patokan skor 1,96 yang merupakan batas nilai (nilai kritis) yang dapat diinterpretasikan secara statistik pada tingkat alpha 5\% dan untuk sepasang indikator melalui prediction error yang substansial (Husain T. , 2017). Setelah model telah memenuhi syarat pada uji kelayakan (goodness-of fit) maka persamaan struktural diturunkan ke dalam pengujian hipotesis untuk menjawab pertanyaan penelitian dengan membandingkan t-value dengan t-critical $(>1,96)$. Analisis data ini menggunakan bantuan perangkat lunak LISREL Versi 8.72 .

\section{Hasil Penelitian}

Jumlah mahasiswa yang mensubmit online yang tersimpan dalam timestamp Google Drive serta memenuhi kriteria sebanyak 77 orang. Sampel ini telah memenuhi kriteria dalam uji multivariat yang populasinya tidak diketahui jumlahnya secara pasti, mensyaratkan 5 (lima) kali variabel yang dianalisis atau indikator pertanyaan (Hair, Black, Babin, \& Anderson, 2010).

Tabel 1. Demografi Responden

\begin{tabular}{|l|c|c|c|}
\hline \multicolumn{2}{|c|}{ Kategori } & Jumlah & Persentase \\
\hline Jenis Kelamin & Pria & 16 & $20,8 \%$ \\
& Wanita & 61 & $79,2 \%$ \\
\hline Usia & $18-25$ tahun & 57 & $74 \%$ \\
& $26-30$ tahun & 13 & $16,9 \%$ \\
& $31-40$ tahun & 5 & $6,5 \%$ \\
& $>40$ tahun & 2 & 2,6 \\
\hline Pendidikan & S1 & 70 & $90,9 \%$ \\
& S2 & 3 & $3,9 \%$ \\
\hline Perangkat & PC & 19 & $24,7 \%$ \\
untuk & Laptop / Netbook & 38 & $48,1 \%$ \\
mengakses & Smartphone & 55 & $70,2 \%$ \\
\hline Frekgle Drive $)$ & & & \\
Penggunsi & $<1$ kali dalam & 18 & $23,4 \%$ \\
Google Drive & sehari & & \\
& 1 kali dalam sehari & 27 & $35,1 \%$ \\
& 1 kali dalam & 9 & $11,7 \%$ \\
& seminggu & & \\
& 1 kali dalam 15 hari & 3 & $3,9 \%$ \\
& 1 kali dalam sebulan & 7 & $9,1 \%$ \\
& $>1$ kali dalam & 13 & $16,9 \%$ \\
& sehari & & \\
\hline
\end{tabular}

(Sumber: Data Diolah, 2019)

Dengan memanfaatkan informasi dari karakteristik responden bahwa mayoritas responden adalah wanita dan responden memiliki usia produktif yang sedang menempuh endidikan jenjang Strata 1. Mayoritas pengguna layanan Google Drive menggunakan SmartPhone 
dengan frekuensi penggunaan yang cukup beragam.

Tabel 2. Statistik Deskriptif

\begin{tabular}{|l|c|c|c|}
\hline $\begin{array}{c}\text { Variabel } \\
\text { Penelitian }\end{array}$ & $\begin{array}{c}\text { Skor } \\
\text { Rata-Rata }\end{array}$ & $\begin{array}{c}\text { Skor } \\
\text { Tengah }\end{array}$ & $\begin{array}{c}\text { Skor } \\
\text { Deviasi }\end{array}$ \\
\hline Kualitas Informasi & 15,47 & 15 & 1,465 \\
\hline Kualitas Sistem & 15,47 & 15 & 1,997 \\
\hline Kualitas Layanan & 9,05 & 9 & 1,327 \\
\hline Kepuasan Mahasiswa & 9,25 & 9 & 1,053 \\
\hline
\end{tabular}

(Sumber: Data Diolah, 2019)

Statistik deskriptif variabel Kualitas Informasi, Kualitas Sistem dan Kualitas Layanan masing-masing menghasilkan skor mean sebesar $15,47,15,45$ dan 9,05 yang lebih besar dari skor median, artinya rata-rata jawaban responden berkisar pada rentang setuju dan sangat setuju terhadap layanan Google Drive sebagai media penyimpanan. Variabel Kepuasan memiliki nilai mean sebesar 9,25 yang berarti responden sangat setuju responden setuju atas layanan Google Drive yang mencerminkan IS Success Model (Delone \& McLean, 2003).

Tabel 3. Hasil Uji Kualitas Instrumen Penelitian

\begin{tabular}{|c|c|c|c|c|c|}
\hline \multicolumn{2}{|c|}{ Nilai SLF } & Hasil & \multicolumn{2}{|c|}{$\begin{array}{c}\text { Nilai SLF } \\
\text { (Uji Ulang) }\end{array}$} & Hasil \\
\hline \multirow[t]{2}{*}{$\mathrm{X} 1$} & 0,23 & valid & $\mathrm{X} 1$ & 0,21 & tidak valid \\
\hline & 0,14 & tidak valid & $\mathrm{X} 1$ & & - \\
\hline $\mathrm{X} 2$ & 0,31 & valid & & & \\
\hline X3 & 0,18 & tidak valid & $\mathrm{X} 3$ & 0,34 & valid \\
\hline $\mathrm{X} 4$ & 0,33 & valid & & & \\
\hline $\mathrm{X} 5$ & & & $\mathrm{X} 5$ & 0,31 & valid \\
\hline \multicolumn{4}{|c|}{ Construct Reliability $(\mathrm{CR})=0,880$} & \multicolumn{2}{|c|}{$\begin{array}{c}0,880>0,4, \\
\text { maka reliabel }\end{array}$} \\
\hline X6 & 0,35 & valid & X6 & 0,35 & valid \\
\hline X7 & 0,22 & tidak valid & & & \\
\hline $\mathrm{X} 8$ & 0,39 & valid & $\mathrm{X} 8$ & 0,39 & valid \\
\hline $\mathrm{X} 9$ & 0,42 & valid & X9 & 0,43 & valid \\
\hline $\mathrm{X} 10$ & 0,43 & valid & $\mathrm{X} 10$ & 0,44 & valid \\
\hline \multicolumn{4}{|c|}{ Construct Reliability $(\mathrm{CR})=0,566$} & \multicolumn{2}{|c|}{$\begin{array}{c}0,566>0,4, \\
\text { maka reliabel }\end{array}$} \\
\hline $\mathrm{X} 11$ & 0,42 & valid & $\mathrm{X} 11$ & 0,41 & valid \\
\hline $\mathrm{X} 12$ & 0,42 & valid & $\mathrm{X} 12$ & 0,43 & valid \\
\hline $\mathrm{X} 13$ & 0,46 & valid & $\mathrm{X} 13$ & 0,36 & valid \\
\hline \multicolumn{4}{|c|}{ Construct Reliability $(\mathrm{CR})=0,601$} & \multicolumn{2}{|c|}{$\begin{array}{c}0,601>0,4, \\
\text { maka reliabel }\end{array}$} \\
\hline Y1 & 0,38 & valid & Y1 & 0,41 & valid \\
\hline $\mathrm{Y} 2$ & 0,33 & valid & Y2 & 0,31 & valid \\
\hline Y3 & 0,19 & tidak valid & & & \\
\hline \multicolumn{4}{|c|}{ Construct Reliability $(\mathrm{CR})=0,667$} & \multicolumn{2}{|c|}{$\begin{array}{c}0,667>0,4, \\
\text { maka reliabel }\end{array}$} \\
\hline
\end{tabular}

(Sumber: Data Diolah, 2019)

Hasil uji kualitas instrumen melalui uji validitas dan reliabilitas data setelah dilakukan pengujian validitas ulang yaitu 11 (sebelas) menghasilkan nilai SLF yang lebih besar (>) dari 0,03 pada sampel 77 mahasiswa. Di samping itu, item-item dalam variabel yang diteliti menghasilkan skor construct reliability yang lebih besar (>) dari 0,40, sehingga keseluruhan butir pernyataan yang dibentuk adalah sah atau layak uji dan instrumen telah reliable atau handal untuk diuji sebagai model penelitian.

Tabel 4. Hasil Uji Kesesuaian Model (Overall)

\begin{tabular}{|c|c|c|c|}
\hline \multicolumn{2}{|c|}{$\begin{array}{c}\text { Indeks Pengukuran | Cut } \\
\text { off }\end{array}$} & Skor & Kesimpulan \\
\hline Chi-Square $\left(\chi^{2}\right)$ & kecil & 115,85 & poor fit \\
\hline$p$-value & $>0,50$ & 0,0000 & poor fit \\
\hline GFI & $>0,90$ & 0,78 & poor fit \\
\hline RMSEA & $<0,05$ & 0,16 & poor fit \\
\hline RMR & $<0,05$ & 0,024 & close fit \\
\hline Standardized RMR & $\leq 0,08$ & 0,092 & marginal fit \\
\hline AGFI & $\geq 0,90$ & 0,62 & poor fit \\
\hline NFI & $\geq 0,90$ & 0,87 & poor fit \\
\hline TLI atau NNFI & $\geq 0,95$ & 0,86 & poor fit \\
\hline CFI & $\geq 0,90$ & 0,90 & good fit \\
\hline RFI & $\geq 0,95$ & 0,81 & marginal fit \\
\hline PGFI & $>0,90$ & 0,45 & poor fit \\
\hline PNFI & $0,6-0,9$ & 0,6 & good fit \\
\hline $\mathrm{CMIN} / \mathrm{dF}$ & $<2,00$ & 3,514 & poor fit \\
\hline
\end{tabular}

(Sumber: Data Diolah, 2019)

Hasil uji kesesuaian (overall) yang dihasilkan oleh output program LISREL 8.72 menghasilkan skor Chi-Square $\left(\chi^{2}=111,85\right.$ dengan p-value sebesar 0,00000, skor RMSEA adalah 0,16, sementara skor RMR dan standardized 0,024 dan 0,092, artinya model menunjukkan kecukupan atau masih dinilai cocok. Skor GFI dan AGFI hanya sebesar 0,90 dan 0,78. Skor dari masing-masing NFI, TLI atau NNFI, CFI, dan RFI hanya memenuhi kriteria marginal fit yaitu antara 0,80 s.d. 0,90 pada CFI dan RFI serta nilai PNFI yang mengindifikasikan good fit. Secara overall, model ini dapat diterima tanpa dilakukan respesifikasi model.

Hasil Output program LISREL 8.72 atas variabel Kepuasan Mahasiswa dihasilkan melalui persamaan berikut ini:

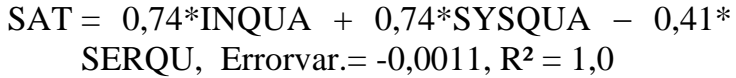

Hasil persamaan struktural diperoleh nilai $\mathrm{R}^{2}$ sebesar 1,00 yang berarti model mampu menjelaskan perubahan pada konstruk yang dipengaruhi. 


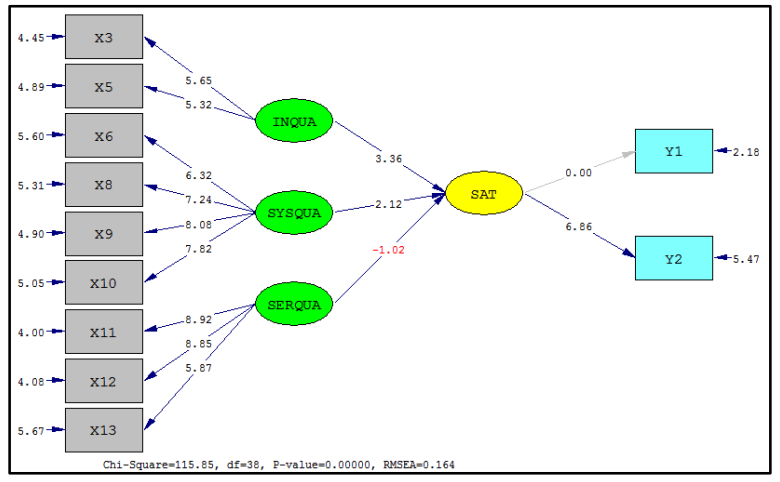

Gambar 3. Path Diagram (Output Lisrel 8.72)

Hubungan antarkonstruk dinyatakan signifikan secara statistik pada level $\alpha$ kurang dari (<) 0,05 atau memiliki t-value lebih besar dari (>) dari nilai t-kritis $(1,96)$. T-value pada pembuktian $\mathrm{H}_{1}$ menghasilkan skor 2,36, lebih besar dari dari nilai kritis $(1,96)$ sehingga menerima hipotesis alternatif tersebut. Artinya kualitas informasi memiliki pengaruh pada kepuasan mahasiswa. $\mathrm{T}$. value pada pembuktian $\mathrm{H}_{2}$ menghasilkan skor 2,32, lebih besar dari dari nilai kritis $(1,96)$ sehingga menerima hipotesis alternatif tersebut. Artinya kualitas sistem memiliki pengaruh pada kepuasan mahasiswa. Akan tetapi T-value pada pembuktian $\mathrm{H}_{3}$ menghasilkan skor minus 1,02, lebih kecil dari dari nilai kritis $(1,96)$ sehingga menolak hipotesis alternatif tersebut. Artinya kualitas layanan tidak memiliki pengaruh pada kepuasan mahasiswa.

Tabel 5. Matriks Korelasi antar Variabel

\begin{tabular}{ccc}
\hline $\begin{array}{c}\text { Hubungan antar } \\
\text { Variabel }\end{array}$ & $\begin{array}{c}\text { Nilai Pearson's } \\
\text { Correlation }\end{array}$ & $\begin{array}{c}\text { Probabilitas } \\
\text { Signifikansi }\end{array}$ \\
\hline INQUA $\rightarrow$ SAT & 0,598 & 0,000 \\
SYSQUA $\rightarrow$ SAT & 0,665 & 0,000 \\
SERQUA $\rightarrow$ SAT & 0,678 & 0,000 \\
\hline Sumber:
\end{tabular}

(Sumber: Data Diolah, 2018)

Hasil uji matriks korelasi antar IS Success Model dengan kepuasan mahasiswa menghasilkan nilai koefisien korelasi (R) tertinggi adalah kualitas layanan diikuti dengan kualitas sistem masing-masing skor yaitu 0,678 dan 0,665 sementara variabel kualitas informasi memiliki skor $\mathrm{R}$ terendah yaitu 0,598. Hasil ini menunjukkan bahwa keseluruhan variabel yang dirumuskan pada framework of IS Success Model memiliki hubungan positif yang kuat terhadap variabel Kepuasan Mahasiswa.

\section{Simpulan}

Uji Model Keberhasilan penggunaan layanan Google Drive, menghasilkan intisari sebagai berikut

1. Keseluruhan konstruk IS Success Model yang diuji, hanya kualitas informasi dan kualitas sistem yang memiliki pengaruh positif secara signifikan pada variabel kepuasan mahasiswa sementara kualitas layanan tidak memiliki pengaruh signifikan.

2. Ketiga konstruk dapat dinyatakan sebagai determinan yang berpengaruh terhadap kepuasan mahasiswa pengguna Google Drive nilai koefisien korelasi masing-masing lebih besar dari (>) 0,6.

\section{Saran Penelitian}

Simpulan penelitian di atas menghasilkan beberapa saran untuk penelitian mendatang dengan agenda:

1. Merumuskan kembali IS Success Model untuk dengan pengembangan model atau teori dengan objek yang berbeda serta melibatkan variabel manifes (pengukuran) yang lebih banyak.

2. Perumusan ulang teknik sampling dalam teknik analisis data lainnya seperti structural equation model (SEM) berbasis general least square (GLS).

3. Mengembangkan IS Success Model dengan kajian-kajian lainnya, seperti sistem informasi perpustakaan digital, e-learning atau sistem informasi penggunaan perangkat atau aplikasi lainnya.

\section{Ucapan Terima Kasih}

Peneliti menghaturkan rasa terima kasih kepada Allah SWT (Tuhan Yang Maha Esa) atas limpahan rahmat dan karunia-Nya yang pada akhirnya artikel ini dapat diselesaikan. Peneliti juga sangat berterima kasih kepada institusi STMIK Swadharma, STMIK Widuri dan Universitas Pamulang yang membantu dan memberikan kesempatan mempublikasikan karya ilmiah ini serta masukan-masukan dalam penyempurnaan isi artikel mengenai layanan Google Drive sebagai media penyimpanan.

\section{References}

Ali, H., \& Limakrisna, N. (2013). Metodologi Penelitian (Petunjuk Praktis untuk Pemecahan Masalah Bisnis, Penyusunan Skripsi, Tesis, dan Disertasi) (1 ed.). Yogyakarta: Deepublish. 
Delone, W. H., \& McLean, E. R. (2003, April). The DeLone and McLean Model of Information Systems Success: A Ten-Year Update. Journal of Management Information Systems, 19(4), 9-30.

Google Developer. (2018). Google Drive APIs REST. Retrieved May 12, 2018, from https://developers.google.com/: https://developers.google.com/drive/v3/web/a bout-sdk

Hair, J. F., Black, W. C., Babin, B. J., \& Anderson, R. E. (2010). Multivariate Data Analysis (7th ed.). New Jersey: Prentice Hall.

Hamdani, Y. Y., \& Kaburuan, E. R. (2017). Buku GSuite. Bandung: Lembaga Sistem Informasi UNIBI.

Hanum, W. S., \& Saifudin, A. (2019, April). Rancang Bangun Aplikasi Panduan Pariwisata Di Kabupaten Banyuwangi. Jurnal Teknologi Sistem Informasi dan Aplikasi, 2(2), 59-65.

Husain, T. (2017, Agustus). Analisis Determinan Faktor-Faktor Yang Mempengaruhi Niat
Penggunaan Software Audit. Jurnal Ilmiah Matrik, 19(2), 131-150.

Husain, T. (2019, Juni). Analisis Layanan Google Scholar Sebagai Bahan Referensi Terhadap Kepuasan Mahasiswa. ULTIMA InfoSys, X(1), 69-75.

Kartikasari, P. (2017, September). Pengaruh Kualitas Sistem Informasi Cyber Campus Terhadap Kepuasan dan Loyalitas Mahasiswa STIKOM Surabaya. Jatisi, 3(2), 169-182.

Prihandi, I. (2017). Tutorial Google Drive Dan Google Apps (1 ed.). Yogyakarta: Deepublish.

Primawati, A. (2015). Analisis Pemanfaatan Groupware Google Drive Untuk Penyelesaian Tugas Kelompok Siswa. In B. O. Lubis, \& K. Yuliantari (Ed.), Seminar Nasional Inovasi dan Tren (SNIT) (pp. A.96-102). Jakarta: Bina Sarana Informatika.

Tentama, F., \& Subardjo. (2018, Februari). Pengujian Validitas Dan Reliabilitas Konstruk Pada Organizational Citizenship Behavior. HUMANITAS, 15(1), 62-71. 